\title{
Painel solar ou teto verde? O que considerar quando for preciso escolher
}

\author{
Solar panel or green roof? What to consider when choosing \\ ¿Panel solar o techo verde? Qué tener en cuenta al elegir
}

Recebido: 28/02/2021 | Revisado: 06/03/2021 | Aceito: 23/03/2021 | Publicado: 31/03/2021

\author{
Nayara Cristina Rosa Amorim \\ ORCID: https://orcid.org/0000-0002-6653-457X \\ Universidade Federal da Bahia, Brasil \\ E-mail: nayaraamorim@ufba.br \\ Matheus Garcia Soares \\ ORCID: https://orcid.org/0000-0002-2701-1450 \\ Universidade Estadual de Santa Cruz, Brasil \\ E-mail: mgsoares@uesc.br
}

\begin{abstract}
Resumo
O objetivo deste artigo é comparar as vantagens e as desvantagens da implantação de painéis solares e tetos verdes em coberturas residenciais. Busca-se amparar a tomada de decisão, quando o projeto arquitetônico possui área reduzida, ou limite de investimento, sendo necessário a escolha entre as duas tipologias. O estudo tem como base conceitual o entendimento de infraestrutura verde e serviços ecossistêmicos. O objeto de estudo é o projeto de uma casa, com área de cobertura de $100 \mathrm{~m}^{2}$, situada na cidade de Ilhéus - Bahia - Brasil, bem como as características de infraestrutura e mercado da cidade. A pesquisa utiliza o método comparativo, e tem como parâmetros: custo de implantação; necessidade de manutenção; eficiência; serviços ecossistêmicos obtidos; cuidados necessários e aspectos de inserção no projeto e na paisagem. São utilizados dados bibliográficos e pesquisas de mercado. Como resultado constata-se que, no geral, a escolha entre as tipologias pode variar de acordo com os princípios do projeto arquitetônico.
\end{abstract}

Palavras-chave: Painel solar; Teto verde; Infraestrutura verde.

\begin{abstract}
The purpose of this article is to compare advantages and disadvantages of deploying solar panels and green roofs in residential coverages. The aim is to support decision-making, where the architectural design has reduced area, or limit investment, being necessary to choose between the two types. The study is based on the conceptual understanding of green infrastructure and ecosystem services. The object of study is the design of a house, with a coverage area of 100 $\mathrm{m}^{2}$, located in the city of Ilhéus - Bahia - Brasil, as well as the city's infrastructure and market characteristics. The research uses the comparative method, and has as parameters: implementation cost; maintenance requirements; efficiency; ecosystem services obtained; necessary care and aspects of insertion in the project and the landscape. Bibliographic data and market research are used. As a result, it appears that, in general, the choice between typologies can vary according to the principles of architectural design.
\end{abstract}

Keywords: Solar panel; Green roof; Green infrastructure.

\begin{abstract}
Resumen
El propósito de este artículo es comparar las ventajas y desventajas de implementar paneles solares y techos verdes en techos residenciales. Busca apoyar la toma de decisiones, cuando el proyecto arquitectónico tiene un área reducida, o límite de inversión, por lo que es necesario elegir entre los dos tipos. El estudio se basa en la comprensión conceptual de la infraestructura verde y los servicios de los ecosistemas. El objeto de estudio es el diseño de una casa, con un área de cobertura de $100 \mathrm{~m}^{2}$, ubicada en la ciudad de Ilhéus - Bahia - Brasil, así como características de la infraestructura y de mercado de la ciudad. La investigación utiliza el método comparativo y tiene como parámetros: costo de implantación; necesidad de mantenimiento; eficiencia; servicios ecosistémicos obtenidos; cuidados necesarios y aspectos de inserción en el proyecto y el paisaje. Se utilizan los datos bibliográficos y de investigación de mercado. Como resultado, parece que, en general, la elección entre tipologías puede variar según los principios del proyecto arquitectónico.
\end{abstract}

Palabras clave: Panel solar; Techo verde; Infraestructura verde.

\section{Introdução}

Duas estratégias ou tecnologias têm dividido e disputado espaço nos telhados das edificações urbanas, os painéis solares e os tetos verdes. A primeira alternativa, os painéis solares, são formados por células fotovoltaicas que transformam a 
energia solar em energia elétrica, uma produção descentralizada e alternativa que pode diminuir a demanda de geração e transmissão da energia das hidrelétricas, principal fonte energética brasileira. A segunda os tetos verdes, são focados na diminuição do escoamento pluvial, aumento da evapotranspiração, aumento da umidade e captação de águas para reuso. Essas duas estratégias podem ser pensadas e projetadas de forma articulada, entretanto quando o projeto possui área reduzida ou limite de investimento, é preciso escolher entre essas duas possibilidades.

O objetivo deste artigo é comparar os custos, as vantagens e as desvantagens da implantação de painéis solares e tetos verdes em coberturas de projetos residenciais.

A infraestrutura urbana, ao assumir uma diretriz mais integrada à paisagem, à escala local e ao ambiente - e, portanto, mais "verde" - permeia o tecido urbano criando uma malha vegetal através de tipologias paisagísticas como: tetos verdes, jardins de chuva, biovaletas, produção energética solar, eólica, baseada em biomassa. São estratégias multifuncionais que contribuem para a regulação dos fluxos de água, beneficiam a gestão de energia, contribuindo para qualidade da vida urbana e aumento da biodiversidade. Esses preceitos são a base da infraestrutura verde, que pretende reestruturar um mosaico de áreas verdes fragmentadas, dando suporte para funções ecológicas, culturais e o fornecimento de serviços ecossistêmicos (Benedict et al., 2006; Ahern, 2007).

Serviços ecossistêmicos (SE) são recursos naturais que sustentam e/ou contribuem para a saúde e o bem-estar humano (Haines-Young \& Potschin, 2017; Fisher, et al., 2009). Observa-se que os SE são, frequentemente, uma função sob a perspectiva do beneficiário, mas não têm que obrigatoriamente ser utilizados pelo homem, são os processos ecológicos ou funções que podem, ou não, afetar o bem-estar humano (Fisher, et al., 2009). Também é importante o entendimento de que os serviços prestados pela natureza nem sempre são benéficos para o ecossistema ou para a população, podendo trazer desserviços ou problemas ambientais.

É importante compreender que o entendimento de serviços ecossistêmicos é diferente de serviços ambientais, que são de consultoria, educação, monitoramento e avaliação, prestados por agentes públicos e privados, que têm impacto na mensuração, prevenção, minimização ou correção de danos aos serviços ecossistêmicos (Barreto, et al., 2020). O instrumento econômico de Pagamentos por Serviços Ambientais (PSA), é um mecanismo que defende que as pessoas responsáveis pela preservação ambiental devem receber benefícios, pois estão colaborando para a consecução do direito fundamental ao meio ambiente ecologicamente equilibrado (Barreto, et al., 2020). Entretanto, o PSA ainda é um instrumento pouco difundido em alguns estados brasileiros, principalmente na Região Nordeste (Barreto, et al., 2020).

\section{Metodologia}

A pesquisa utiliza o método comparativo, com análise qualitativa, que consiste em investigar coisas ou fatos e explicá-los segundo suas semelhanças e suas divergências em elementos constantes, abstratos e gerais, propiciando investigações de caráter indireto (Fachin 2001; Pereira, et al. 2018). Buscando amparar escolhas projetuais, em situações onde se é necessário escolher entre a implantação de painéis solares e tetos verdes.

O trabalho tem como objeto de análise o projeto de uma edificação de uso residencial, de um pavimento, com área de cobertura de $100 \mathrm{~m}^{2}$, situada na cidade de Ilhéus - Bahia. A cidade de Ilhéus está em 44m acima do nível do mar e apresenta um clima tropical. Possui médias pluviométricas anuais entre 2.000 e 2.400 milímetros, com presença de chuvas até nos meses mais secos. E uma temperatura média anual superior a $24^{\circ} \mathrm{C}$ (Franco, 2008).

A metodologia adota a revisão bibliográfica de artigos, manuais, teses acadêmicas e das legislações brasileiras pertinentes. Os autores de suporte para o entendimento de painéis solares foram: Marques (2017), ANEEL (2021), Cerqueira \& Gomes (2019). Para a abordagem de tetos verdes: Mendes (2017), Pinheiro (2017), Oliveira, et al. (2017), Enzi et al. (2017), Bonzi (2015). 
Também são considerados na pesquisa alguns dados de caráter qualitativo, como as características do município e dados de infraestrutura disponível. Ilhéus apresenta 65.9\% de domicílios com esgotamento sanitário adequado, 49.1\% de domicílios urbanos em vias públicas com arborização e apenas $23.1 \%$ de domicílios urbanos em vias públicas com urbanização adequada (presença de bueiro, calçada, pavimentação e meio-fio) (IBGE, 2010). Os dados de infraestrutura do município evidenciam a necessidade de se pensar em projetos residenciais mais integrados com a paisagem, que considerem as limitações da infraestrutura urbana e se utilizem de soluções baseadas na natureza (Enzi, et al., 2017).

Ao final, foi desenvolvido um quadro comparativo entre a utilização de painéis solares e tetos verdes, onde se utiliza como parâmetro: implantação, necessidade de manutenção, eficiência, serviços ecossistêmicos obtidos e aspectos de inserção no projeto arquitetônico e na paisagem urbana.

\section{Resultados e Discussão}

\subsection{Painel solar}

A utilização de técnicas de infraestrutura verde pode beneficiar a gestão energética de diversas formas, seu maior impacto não ocorre diretamente na geração de energia, é resultado dos benefícios gerados tanto no meio urbano como nas áreas não urbanizadas - como redução do consumo energético demandado para concessionária de energia, seja por edifícios ou pelos sistemas gestores das águas e da preservação e/ou requalificação dos sistemas hídricos (Marques, 2017).

A instalação de unidades de microgeração solar em ambiente urbano vem aumentando ao longo dos anos e se popularizando em consumidores do tipo residencial. Entende-se como unidade de microgeração o conjunto de placas fotovoltaicas e inversor de frequência. As placas solares transformam a energia solar em energia elétrica contínua e o inversor de frequência é o responsável por transformar a energia contínua em alternada e adequar os níveis de tensão para que se possa efetuar a ligação no sistema elétrico.

Atualmente, segundo a ANEEL (2021), o município de Ilhéus possui 220 unidades geradoras, o que equivale a uma potência instalada de $1435,77 \mathrm{~kW}$, sendo que deste montante $905 \mathrm{~kW}$ correspondem a microgeração residencial, ou seja, $63 \%$ da potência instalada se destina a residências, $32 \%$ a unidades comerciais e o restante de $5 \%$ se divide entre indústria, uso rural e órgãos públicos.

Antes de se pensar na instalação das placas fotovoltaicas para construções já existentes, recomenda-se a realização de um estudo de eficiência energética a fim de analisar quais melhorias poderiam ser realizadas antes da instalação. Esta análise prévia pode mostrar que a substituição de alguns eletrodomésticos de maior uso, como geladeira e máquina de lavar por versões mais eficientes, geram uma economia no consumo de energia. Uma vez analisada a instalação, um dimensionamento mais preciso da microgeração pode ser alcançado.

O ponto de partida do dimensionamento da unidade microgeradora começa na análise do histórico de consumo de energia da residência em que se pretende instalar, caso se trate de uma construção já existente ou no projeto elétrico de uma futura construção. Os dados de consumo ou o projeto elétrico serão a base para se determinar a quantidade de painéis solares e consequentemente a potência da unidade de microgeração. Assim, para efeitos de demonstração e facilidade do cálculo de dimensionamento, considerou-se um consumidor residencial trifásico, com consumo mensal de energia de $300 \mathrm{kWh}$.

O trabalho desenvolvido por Cerqueira \& Gomes (2019), desenvolve uma análise sobre os aspectos das microgerações de energia elétrica para uma residência no município de Ilhéus-BA. Além da análise da energia gerada ao longo de um ano, o trabalho também apresenta uma forma de se calcular a potência a ser instalada com base no consumo da residência, apresentado a seguir, na Equação 1.

$$
\mathrm{Pw}=(\mathrm{Pd} * \mathrm{Mp}) / \mathrm{Pq}
$$


Onde:

$\mathrm{Pw}=$ potência da unidade de microgeração de energia elétrica fotovoltaica $(\mathrm{W})$;

$\mathrm{Pd}=$ produção de energia elétrica fotovoltaica diária $(\mathrm{kWh} / \mathrm{dia}) ;$

$\mathrm{Mp}=$ potência por $\mathrm{m}^{2}$ do painel solar a ser utilizado $(\mathrm{W})$;

$\mathrm{Pq}=$ produção de energia elétrica fotovoltaica diária por área de painel solar $\left(\mathrm{kWh} / \mathrm{m}^{2} / \mathrm{dia}\right)$.

O valor de Pd é definido através do consumo de energia elétrica, assim, com base no valor já estipulado de $300 \mathrm{kWh}$ pode-se escolher a quantidade de energia a ser gerada por dia. Para um dimensionamento preciso não se faz necessário a geração de $100 \%$ do valor consumido, pois independentemente da quantidade excedente gerada, sempre será necessário o pagamento da taxa de disponibilidade de energia elétrica que varia de acordo com a classe do consumidor. O custo de disponibilidade equivale a um consumo de $30 \mathrm{kWh}$ para consumidores monofásicos, $50 \mathrm{kWh}$ para bifásico e $100 \mathrm{kWh}$ para trifásico, de acordo com a resolução normativa da ANEEL n ${ }^{\circ} 414$ de 2010. Neste contexto, considerando um dimensionamento preciso, subtrai-se a taxa de disponibilidade do valor de consumo mensal e divide-se pela quantidade de dias do mês $\mathrm{Pd}=(300$ $-100) / 30=6,67 \mathrm{kWh} /$ dia.

O segundo valor da equação Mp é determinado pelo tipo de painel utilizado na instalação. Atualmente existem painéis de diversas potências, assim, neste exemplo utilizou-se um painel de 330 $\mathrm{W}$ com uma área de 1,98 $\mathrm{m}^{2}$, o que proporciona $\mathrm{Mp}=$ $330 / 1,98=166,67 \mathrm{~W} / \mathrm{m}^{2}$. Os dados de potência e área são fornecidos pelo fabricante do painel.

O último termo da equação Pd é encontrado por meio da multiplicação da eficiência da unidade fotovoltaica (conjunto da placa mais o inversor) e a irradiação recebida na superfície inclinada das placas, para mais detalhes ver o trabalho de Gomes e Cerqueira (2019). Para a cidade de Ilhéus o valor de Pd é aproximadamente $0,88 \mathrm{kWh} / \mathrm{m}^{2} / \mathrm{dia}$.

Resolvendo Equação 1, com base nos valores apresentados obtém-se um valor estimado para a potência da unidade de microgeração de 1263,3W. Assim, para o exemplo, será necessário a instalação de quatro painéis solares de 330W, o que ocupa uma área de cobertura de 7,92 $\mathrm{m}^{2}$.

É importante destacar que o valor de Pw encontrado refere-se a uma estimativa média de produção diária de energia. Em um sistema real este valor irá variar de acordo com as estações do ano, nos meses referentes a primavera, verão e início do outono espera-se uma produção de energia acima da média e nos meses referentes ao fim do outono e inverno uma produção abaixo da média como visto em Gomes \& Cerqueira (2019).

A instalação das placas fotovoltaicas pode ser realizada em construções já existentes podendo se adequar facilmente a qualquer tipo de cobertura ou até no solo. O que pode ser considerado uma vantagem desta tipologia, entretanto os custos de instalação irão variar de acordo com o tipo da cobertura. Os cuidados e a manutenção das placas são relativamente simples, o principal deles é a limpeza da superfície da placa a fim de evitar que esta fique com acúmulo de sujeira, o que compromete a eficiência da geração, uma vez que impede que a luz atinja a célula fotovoltaica. A periodicidade do processo de limpeza irá depender das condições do local da instalação podendo ser efetuada anualmente ou a cada seis meses.

\subsection{Teto verde}

Os tetos verdes, coberturas verdes, ou telhados verdes, consistem na implantação de jardins (vegetados ou não) sobre a cobertura de edificações. Existem dois tipos de tetos verdes, os intensivos e os extensivos. Tetos verdes extensivos são aqueles que utilizam vegetação gramínea e herbácea com porte variando de 5 a 20 centímetros (espécies com raízes superficiais), sobre uma camada de substrato que possui entre 5 e 15 centímetros de profundidade (Bonzi, 2015). Tetos verdes intensivos são caracterizados pelo uso de herbáceas, arbustos e árvores de pequeno porte, apresentando maior biodiversidade (Pinheiro, 2017). Os jardins intensivos necessitam de uma camada de substrato mais profunda, com mais de 15 centímetros de 
profundidade, para suporte das raízes, o que gera mais custos de implantação e manutenção e exige um reforço estrutural para sustentar o peso depositado sobre a laje (Mendes, 2017). O presente estudo tem como enfoque tetos verdes extensivos.

$\mathrm{O}$ design de um teto verde extensivo compreende cinco principais camadas. A camada de substrato onde a vegetação cresce $(5$ a $15 \mathrm{~cm}$ ). A camada da manta geotêxtil, um filtro que previne a difusão de partículas de solo e raízes para a camada inferior. A camada drenante que deve possuir uma inclinação entre 0,5 e $1 \%$, para direcionamento da água de chuva acumulada. Mais uma camada de manta geotêxtil para impedir a passagem de alguma partícula que tenha atravessado as camadas anteriores. E por fim a camada de proteção/impermeabilização, que evita danos mecânicos e infiltração da água na laje (Mendes, 2017; Pinheiro, 2017). A Figura 1 ilustra a composição do teto verde:

Figura 1: Perfil esquemático de um teto verde.

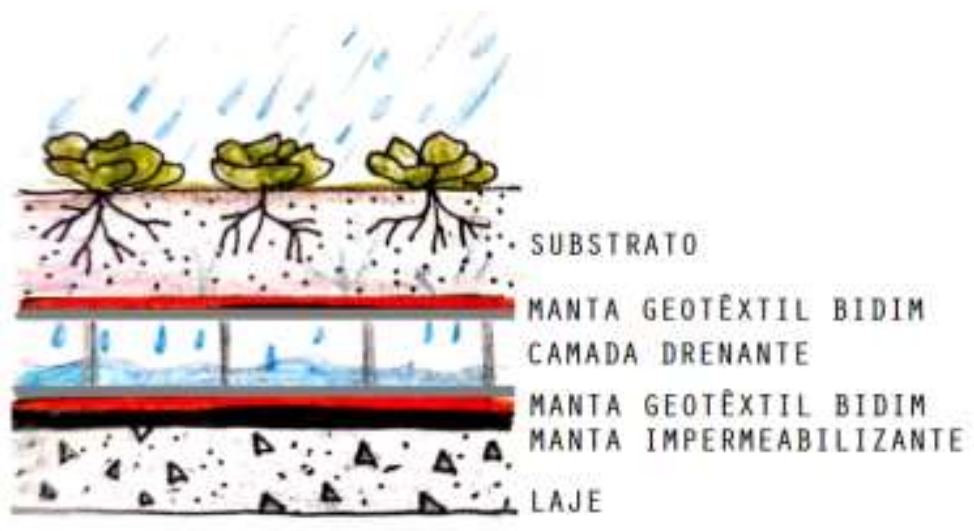

Desenho sem escala. Fonte: Autores.

Entre os benefícios ambientais da implantação do teto verde destaca-se o manejo das águas pluviais. A tipologia atua no controle hidráulico retendo uma parcela das águas, contribuindo para redução do escoamento sobre superfícies pavimentadas (rua e calçadas) e contribuem para o aumento da taxa de evaporação local (Enzi, et al., 2017; Pinheiro, 2017; Bonzi, 2015). Quando a vegetação está implantada a tipologia oferece habitat para a fauna (Mendes, 2017; Bonzi, 2015). E contribui para redução das ilhas de calor urbano, absorvendo uma parcela da radiação solar (Oliveira, et al., 2017).

Também são considerados os atributos paisagísticos, os tetos verdes formam espaços de lazer e recreação, que favorecem aproveitar a vista para o entorno. Possibilitam o cultivo de hortaliças, ervas de uso medicinal e de uso ritualístico, contribuindo para segurança alimentar, fomentando a cultura e a diversidade religiosa. Além de serem espaços que podem abrigar atividades domésticas como lavagem e secagem de roupas.

É importante que os tetos verdes sejam associados a espaços de captação e armazenagem de água de chuva, principalmente em cidades como Ilhéus, que possui chuvas constantes e insuficiência das infraestruturas de manejo das águas pluviais. A água armazenada pode ser utilizada para rega do próprio teto verde nos dias sem chuva.

Com relação a manutenção dos tetos verdes são consideradas duas modalidades. A primeira referente aos cuidados com a vegetação (irrigação, poda, adubação, replantio, etc), que são realizados semanalmente ou mensalmente. A segunda referente a manutenção da camada impermeabilizante aplicada sobre a laje, a durabilidade varia de acordo com as especificações do fornecedor, mas em geral a manta asfáltica apresenta vida útil com estanqueidade total entre 5 a 10 anos, após esse período ela perde a flexibilidade e se torna quebradiça, apresentando falhas na fixação o que pode acarretar em problemas, como infiltrações e vazamentos. Nesse procedimento é necessário retirar todas as camadas do jardim para reaplicar a manta impermeabilizante, o que pode ser considerado uma desvantagem da tipologia. Entretanto, estudos apontam que presença do jardim sobre a manta estende a vida da impermeabilização do telhado (Enzi, et al., 2017; Pinheiro, 2017; Bonzi, 
2015).

\subsection{Quadro Comparativo}

A escolha projetual de implantar o painel solar ou um teto verde, impacta em outras características do projeto. Por exemplo, ao adotar um painel solar é preciso evitar o sombreamento do telhado, não utilizando árvores de grande porte no entorno, o que pode gerar uma limitação paisagística.

O tamanho de um teto verde é variável, pode ocupar uma parte ou toda a área da cobertura, entretanto, quanto maior a área desse jardim, maiores são seus benefícios. É preciso projetar também uma escada ou rampa de acesso ao telhado. Já a área ocupada pelo painel solar é bem menor e não exige a construção de estruturas para seu acesso.

A Figura 2 ilustra como poderia ser uma cobertura com cada uma das tipologias.

Figura 2: Croqui de planta de cobertura com painel solar e com teto verde.
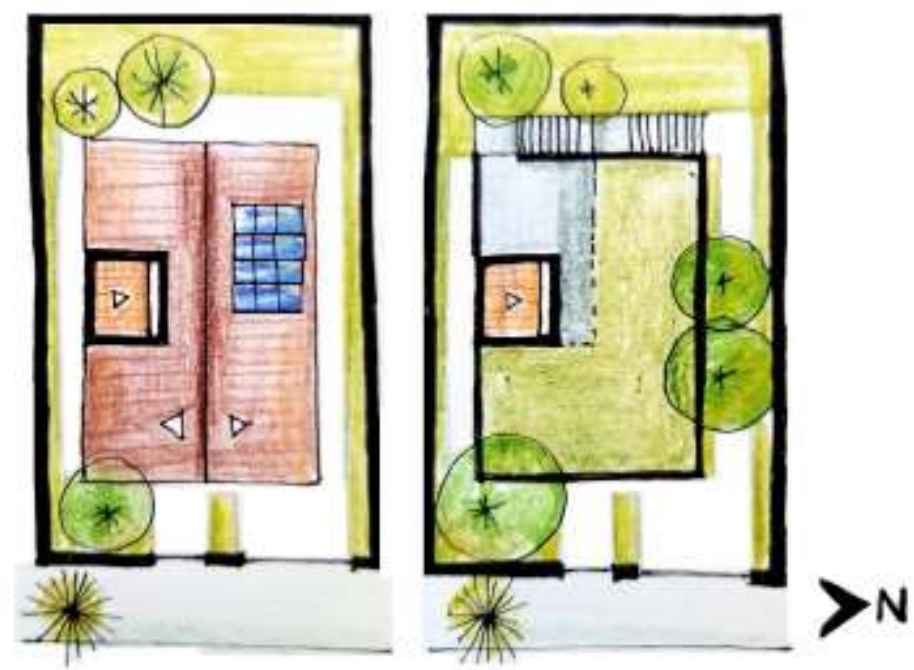

Desenho sem escala. Fonte: Autores (2021).

Na sequência, o Quadro 1 demonstra a aplicação de alguns parâmetros de comparação entre painel solar e teto verde.

Quadro 1: Comparativo entre Painel Solar e Teto Verde.

\begin{tabular}{|c|c|c|}
\hline Parâmetros de comparação & PAINEL SOLAR & TETO VERDE \\
\hline $\begin{array}{c}\text { Materiais necessários para } \\
\text { implantação }\end{array}$ & $\begin{array}{l}\text {-Placas fotovoltaicas } \\
\text {-Inversor ou microinversor } \\
\text {-Medidor de energia bidirecional } \\
\text {-Fios }\end{array}$ & $\begin{array}{l}\text {-Manta impermeabilizante } \\
\text {-Vegetação } \\
\text {-Substrato (terra preta) } \\
\text {-Agregado graúdo (argila expandida) } \\
\text {-Manta de bidim } \\
\text {-Tubulação para escoamento da água residual }\end{array}$ \\
\hline Mão de obra & $\begin{array}{l}\text {-Os custos irão variar de acordo com } \\
\text { o local de instalação das placas (solo } \\
\text { ou telhado) e do tipo de material que } \\
\text { constitui o telhado (cerâmica, } \\
\text { fibrocimento, metálico e laje). }\end{array}$ & $\begin{array}{l}\text {-No momento não existe mão de obra } \\
\text { especializada na região Ilhéus - Itabuna. }\end{array}$ \\
\hline $\begin{array}{l}\text { Periodicidade da } \\
\text { manutenção }\end{array}$ & $\begin{array}{l}\text {-Limpeza da placa de uma vez ao } \\
\text { ano ou a cada seis meses, } \\
\text { dependendo das condições do }\end{array}$ & $\begin{array}{l}\text {-Manutenção da vegetação: semanal. } \\
\text { - Reaplicação da manta impermeabilizante } \\
\text { (manta asfáltica): entre } 5 \text { e } 10 \text { anos. }\end{array}$ \\
\hline
\end{tabular}




\begin{tabular}{|c|c|c|}
\hline & $\begin{array}{l}\text { ambiente como chuvas, poeira, } \\
\text { poluição etc... }\end{array}$ & \\
\hline Desempenho/ tempo & $\begin{array}{l}\text {-Os fabricantes estimam que a placa } \\
\text { fotovoltaica forneça até } 80 \% \text { de sua } \\
\text { potência ao longo de } 25 \text { anos. Uma } \\
\text { perda } 0,8 \% \text { de potência gerada por } \\
\text { ano. }\end{array}$ & $\begin{array}{l}\text {-A tipologia não perde eficiência desde que se } \\
\text { mantenha os cuidados de manutenção (ENZI et } \\
\text { al. 2017). }\end{array}$ \\
\hline $\begin{array}{l}\text { Serviços Ecossistêmicos que } \\
\text { podem ser obtidos }\end{array}$ & $\begin{array}{l}\text {-Provisão de energia elétrica a partir } \\
\text { de fonte renovável. }\end{array}$ & $\begin{array}{l}\text { - Manejo do escoamento superficial; } \\
\text {-Aumento da umidade do ar; } \\
\text {-Aumento da vida útil da impermeabilização; } \\
\text {-Fornecimento de água de reuso; } \\
\text {-Provisão de alimentos; } \\
\text {-Criação de habitats; } \\
\text {-Criação de espaços de lazer. } \\
\text { (BONZI, 2015; OLIVEIRA et al., 2017; } \\
\text { PINHEIRO, 2017). }\end{array}$ \\
\hline $\begin{array}{c}\text { Desvantagens ou cuidados } \\
\text { necessários }\end{array}$ & $\begin{array}{l}\text {-Sem a limpeza periódica dos painéis } \\
\text { solares a geração de energia fica } \\
\text { comprometida diminuindo a sua } \\
\text { eficiência. }\end{array}$ & $\begin{array}{l}\text {-Sem a manutenção da camada } \\
\text { impermeabilizadora podem ocorrer infiltrações } \\
\text { e vazamentos } \\
\text { (ENZI et al. 2017; MENDES, 2017). }\end{array}$ \\
\hline
\end{tabular}

Fonte: Autores (2021).

Percebe-se que a escolha projetual entre painel solar e teto verde não é tão simples, pois envolve vários fatores e parâmetros. Como resultado da pesquisa, constatou-se que quando o projeto prioriza a diminuição de custos com implantação e manutenção, além de uma diminuição nas contas de energia, a melhor opção é o painel solar. Quando o projeto prioriza o uso de uma tipologia mais multifuncional e integrada à paisagem, a melhor opção é o teto verde.

\section{Considerações Finais}

Os tetos verdes algumas vezes são apresentados como parte de compensações ambientais frente a diminuição dos espaços livres urbanos, principalmente os permeáveis e vegetados. Entretanto, apesar dessas tipologias paisagísticas contribuírem para melhoria da qualidade urbana elas não substituem os espaços livres, que desempenham outras funções ecossistêmicas como: recarga de lençóis freáticos, melhoria da qualidade do ar, sombreamento, limpeza da poluição difusa, criação de habitats e ecossistemas mais biodiversos, dentre outros.

O aquecimento das áreas urbanas impacta diretamente no consumo energético, pois sistemas de refrigeração, ventilação e condicionamento de ar precisam funcionar com maior potência e durante períodos mais longos de tempo. Além disso, os aparelhos de ar condicionado contribuem para formação de ilhas de calor, pois, enquanto refrescam o ambiente interno, suas máquinas lançam ar quente no meio externo, contribuindo para o aumento das temperaturas, gerando um círculo vicioso de causa e efeito (Marques, 2017). A diminuição dos espaços livres vegetados nas cidades também contribui para piora da qualidade do ar e o aumento das temperaturas, o que pode acarretar no aumento do uso de aparelhos condicionadores de ar ou ventiladores, o que propicia o crescimento do consumo energético. O que também pode impulsionar o uso de formas de produção de energia alternativas como os painéis solares.

Vale lembrar que as vantagens e desvantagens entre painel solar e teto verde são diferentes quando tratamos da aplicação dessas tipologias em uma construção já existente ou em um projeto a ser implementado. Assunto que pode ser desenvolvido em trabalhos futuros.

Por fim, é importante ressaltar que painéis solares e tetos verdes podem ser projetados e implantados de forma 
articulada, dividindo espaço em uma mesma cobertura, e essa é sempre a melhor opção.

\section{Referências}

Ahern, J. F. (2007). Green Infrastructure for Cities: the spatial dimension. In V. Novotny \& P. Brown (Ed.) Cities of the future: towards integrated sustainable water and landscape management (pp. 267-283). IWA Publishing.

Agência Nacional de Energia Elétrica - ANEEL. (2021). Unidades consumidoras com geração distribuída da Unidade da Federação: BA. http://www2.aneel.gov.br/scg/gd/gd_estadual_detalhe.asp?uf=BA

Barreto, J. B., Freitas, P. Ângela B., Fontgalland, I. L., Macri, L. M. S. R., \& Estrela, T. F. (2020). Pagamentos por Serviços Ambientais (PSA): um estudo acerca da legislação brasileira e da estruturação de acordos. Research, Society and Development, 9(12), e38791211306. https://doi.org/10.33448/rsdv9i12.11306

Benedict, M.A., McMahon, E. T. \& The Conservation Fund (2006). Green Infrastructure: linking landscapes and communities. Island Press.

Bonzi, R. S. (2015). Andar sobre Água Preta: a aplicação da infraestrutura verde em áreas densamente urbanizadas (Dissertação de mestrado). Universidade de São Paulo. Programa de Pós- Graduação em Arquitetura e Urbanismo. São Paulo, SP, Brasil.

Enzi, V., Cameron, B., Dezsényi, P., Gedge, D., Mann, G. \& Pithha, U. (2017). In N. Kabisch et al (Ed.) Nature-Based Solutions and Buildings: the power of surfaces to help cities adapt to climate change and to deliver biodiversity. Nature-Based Solutions to climate change adaptation in urban areas: linkages between science, policy and practice (pp. 159-186) Springer Open.

Fachin O. (2006). Fundamentos de Metodologia (5a ed.). Saraiva.

Franco, G. (2008). Risco a escorregamento de encostas do sítio urbano de Ilhéus (BA) como contribuição ao planejamento urbano. (Dissertação de Mestrado) Universidade Estadual de Santa Cruz. Programa Regional de Pós-Graduação em Desenvolvimento e Meio Ambiente. UESC, Ilhéus.

Fisher, B., Turner, R. K. \& Morling, P. (2009). Defining and classifying ecosystem services for decision making. Ecological Economics, 68(3), 643-653.

doi.org/10.1016/j.ecolecon.2008.09.014

Gomes, R. L. \& Cerqueira, A. H. (2019). Aspectos da microgeração, consumo e produção de energia elétrica fotovoltaica: estudo de caso em uma residência no sul da Bahia. Revista Brasileira de Energia Solar. 10 (1), 26 - 37. https://rbens.emnuvens.com.br/rbens/article/view/252

Haines-Young, R. \& Potschin, M. B. (2017). Common International Classification of Ecosystem Services (CICES) V5.1 and Guidance on the Application of the Revised Structure. https://cices.eu/content/uploads/sites/8/2018/01/Guidance-V51-01012018.pdf.

Instituto Brasileiro de Geografia e Estatística- IBGE (2020). Censo 2010. https://cidades.ibge.gov.br/brasil/ba/ilheus/panorama

Marques, T. (2017). A infraestrutura verde na gestão de energia. In P. R. M. Pellegrino \& N. B. Moura (Org.) Estratégias para uma infraestrutura verde (pp. 213 -241). Manole.

Mendes B. (2017). A paisagem elevada dos tetos verdes. In P. R. M. Pellegrino \& N. B. Moura (Org.) Estratégias para uma infraestrutura verde (pp. 183 212). Manole.

Oliveira, F. C. P., Castanheira, R. G., Rezende, A. L. T., Vasconcellos, C. A. B., Souza, R. O. L. (2017). Comparação da eficiência energética entre uma cobertura verde e um telhado de fibrocimento utilizando simulação computacional. Revista Espacios. $38(1)$, 1-12. http://www.revistaespacios.com/a17v38n01/a17v38n01p01.pdf

Pereira, A. S., Shitsuka, D. M., Parreira, F. J., \& Shitsuka, R. (2018). Metodologia da pesquisa científica. UFSM. https://rep ositorio.ufsm.br/bitstream/handle/1/15824/Lic_Computacao_Metodologia -Pesquisa -Cientifica.pdf?sequence=1

Pinheiro, M. B. (2017). Plantas para infraestrutura verde e o papel da vegetação no tratamento das águas urbanas de São Paulo: identificação de critérios para seleção de espécies (Dissertação de mestrado). Universidade de São Paulo, Programa de Pós- Graduação em Arquitetura e Urbanismo, São Paulo, SP, Brasil. 